\title{
Nutritional Status of Reproductive Women Who Follow Vegetarian Diet in Badung Regency
}

\author{
I G P Wiadnjana ${ }^{1}$, M R R Yanti ${ }^{1}$, P A N K Permatananda ${ }^{1}$ \\ ${ }^{1}$ Faculty of Medicine and Health Science, Universitas Warmadewa, Indonesia \\ *nayakasih@gmail.com
}

\begin{abstract}
Vegetarian diet has become a popular diet among people. However, the diet is known to cause the lack of some nutrients such as protein, iron, and B12, which has the implication on one's nutritional status. When the body's metabolism is high as in times of growth, menstruation, pregnancy and lactation, and women of reproductive age group with vegetarian diets are vulnerable to nutritional deficiencies. The study is aimed to identifying nutritional status women of reproductive age group with vegetarian diets in Badung Regency. The method used in this study is descriptive quantitative, with cross sectional approach. Nutritional status based on Body Mass Index (BMI), Upper Arm Circumference (UAC), and Hemoglobin $(\mathrm{Hb})$ level. Data analysis in the form of frequency distribution table and narrated. The result of measuring the nutritional status obtained is most women of reproductive age group with vegetarian diets have good nutritional status. From these results it is necessary to note the intake of foods and types of food consumed for nutritional needs are met. Foods derived from iron and vitamin $\mathrm{C}$ that facilitate the absorption of iron.
\end{abstract}

Keyword: Nutritional, Reproductive, Vegetarian Diet.

\section{Introduction}

Nutritional status is a condition of one's physical health which can be seen from the measure of the balance between needs and obtained input of nutrients. Based on data from Riset Kesehatan Dasar 2010, the prevalence of malnutrition in the province of Bali is 3.2\% and the prevalence of malnutrition is $19.4 \%$. Groups that are vulnerable to malnutrition problems are pregnant women, toddlers, and reproductive age women [1]. Factors that influence nutritional status are food consumption, nutrition knowledge, and economy [2]. Vegetarianism is a diet that only consumes vegetable products with or without milk and eggs, but overall this type of diet avoids the use of meat, poultry and marine animals [3]. As time goes on, the vegetarian diet becomes increasingly popular.

The vegetarian diet has become a diet that many people have begun to choose along with the increasing public knowledge of the benefits of plant-based diets to reduce the risk of degenerative diseases. However, a vegetarian diet is prone to be lacking the intake of several nutrients, namely protein, iron, zinc, and vitamin B12 which affect nutritional status. When the body's metabolism is high, such as during the period of growth, pregnancy and lactation, reproductive women, especially those who are following a vegetarian diet, is prone to be lacking of a more complete nutrient intake from animal food sources, one of which is iron [4]. According to a study done by Sesanti (2012), it was explained that a body mass index (BMI) of $60 \%$ in women of reproductive age who followed a vegetarian diet was declared undernourished, and as many as $80 \%$ of vegetarian women had low hemoglobin levels [5]. 
Nutritional status can be assessed from anthropometry (Body Mass Index, Upper Arm Circumference, and Lower Skin Fat), clinical, biochemical, and food consumption surveys [6]. Based on these problems, research is conducted on nutritional status in women who follow a vegetarian diet.

\section{Method}

This research was carried out at Asram Sri Nitai Gaurangga, Baha Village, Mengwi District and at Asram Radha Rasesvara, Gerih Village, Abiansemal District (a community of vegetarian communities in Badung Regency). Conducted in October-December 2017, the design of this study was descriptive quantitative research, using cross sectional approach. The population in this study were vegetarian women of reproductive age, from the age of 15-49 with 55 people.

The variables in this study were reproductive age, age, occupation, vegetarianism, BMI, $\mathrm{UAC}$, and $\mathrm{Hb}$ Level. Primary data is collected by using paper sheets entitled "identification of respondents and recording of results of examination". The sheet was made to find out the identity, inclusion criteria and exclusion criteria. Examination of the respondent's height was done by using a height measuring device, namely microtoise with accuracy of $0.1 \mathrm{~cm}$, and weight measurement was done with the scales. The body scales need to be calibrated to zero as a start and have a precision of $0.1 \mathrm{~kg}$. UAC's measurement was done using UAC tape. The hemoglobin level is measured using a digital hemoglobin meter, easy touch. Data analysis is displayed in the form of frequency distribution tables and narrated.

\section{Results And Discussion}

Table 1 described the crosstabulation of nutritional status based on body mass index, upper arm circumference, and hemoglobin level with occupation, age, and vegetarian's duration. From that table, it was found that most respondents had normal nutritional status based on BMI, nutritional status based on the upper arm circumference, and low hemoglobin levels. Nutritional status according to BMI of 15 respondents from the age group 15-19 years showed that $9(69.2 \%)$ respondents had malnutrition. In the age group of 20-35 with 30 respondents, 4 $(30.8 \%)$ respondents had malnutrition, while only 1 (33.3\%) respondents had more than enough nutrition and with 2 respondents $(66.7 \%)$ were said to be obese. In the 36-49 year age group of 10 respondents, $2(100 \%)$ respondents had more than enough nutrition.Nutritional status according to $\mathrm{Hb}$ levels showed that in the age group 15-19 years, as many as 11 (32.4) respondents were known to have low Hb levels and 4 (19.4\%) respondents with normal $\mathrm{HB}$ levels. In the 20-35 year age group, 19 (55.9\%) respondents with low Hb levels and 11 (52.4) respondents had normal $\mathrm{Hb}$ levels. Whereas in the 36-49 year age group, there were $4(11.8 \%)$ respondents with low $\mathrm{Hb}$ levels and 6 (28.6\%) respondents with normal Hb levels. Based on the upper arm circumference, reproductive women who are classified as malnourished in the $15-19$ year age group were as many as $5(1.4 \%)$, while in the $20-35$ year age group were only $2(28.6 \%)$ respondents. Most women of reproductive age have good nutrition, namely ages $15-$ 19 years with $10(0.8 \%)$ respondents, ages $20-35$ years with $28(58.3 \%)$ respondents, and ages $36-49$ years with $10(20.8 \%)$ respondents. 
Nutritional status according to BMI in the working group of 40 respondents. There were $11(84.6 \%)$ respondents who had malnutrition, $28(75.7 \%)$ respondents with normal nutrition, and only $1(33.3 \%)$ respondents had more than enough nutrition. In the group that did not work with 15 respondents, as many as $2(15.4 \%)$ respondents had malnutrition, $9(24.3 \%)$ with normal nutrition, $2(66.7 \%)$ respondents with more than enough nutrition, and $2(100 \%)$ respondents with obesity. Hb levels indicate that of the 40 respondents who have jobs, 26 (76.5\%) respondents with low Hb levels and 14 (66.7\%) respondents with normal Hb levels. While from 15 respondents who did not work, 8 (23.5\%) respondents with low Hb levels and $7(33.3 \%)$ respondents with normal $\mathrm{Hb}$ levels. The frequency of arm circumference shows that out of 40 women of reproductive age who have jobs, 7 (100\%) respondents have less nutrition and as many as $33(68.8 \%)$ respondents have good nutrition. While from 15 women of reproductive age who did not have jobs, all respondents (15) (31.3\%) had good nutrition.

Table 1. Crosstabulation between Nutritional Status Based on BMI, Hemoglobin Level, and Upper Arm Circumference with Occupation, Age, and Vegetarian's Duration

\begin{tabular}{|c|c|c|c|c|c|c|c|c|}
\hline \multirow[t]{2}{*}{$\begin{array}{c}\text { Nutritional } \\
\text { Status }\end{array}$} & \multicolumn{3}{|c|}{ Occupation } & \multicolumn{3}{|c|}{ Age } & \multicolumn{2}{|c|}{$\begin{array}{l}\text { Length in Following } \\
\text { Vegetarian }\end{array}$} \\
\hline & $\begin{array}{c}\text { Working } \\
\mathrm{n}(\%)\end{array}$ & & $\begin{array}{l}\text { lot } \\
\text { king } \\
\%)\end{array}$ & $\begin{array}{c}15-19 \mathrm{y} . \mathrm{o} \\
\text { n }(\%)\end{array}$ & $\begin{array}{c}20-35 \text { y.o } \\
n(\%)\end{array}$ & $\begin{array}{c}36-49 \text { y.o } \\
\text { n }(\%)\end{array}$ & $\begin{array}{c}<10 \text { years } \\
\mathrm{n}(\%)\end{array}$ & $\begin{array}{l}>10 \\
\text { years } \\
\mathrm{n}(\%)\end{array}$ \\
\hline \multicolumn{9}{|c|}{ Body Mass Index (BMI) } \\
\hline Underweigh & t $11(84$ & & $2(15.4$ & $9(69.2)$ & $4(30.8)$ & 0 & $2(15.4)$ & $11(84.6)$ \\
\hline Normal & $28(75$ & & $9(24.3$ & $6(16.2)$ & $25(67.6)$ & $6(16.2)$ & $13(35.1)$ & $24(64.9)$ \\
\hline Overweight & $1(33.3$ & & $2(66.7$ & 0 & $1(33.3)$ & $2(66.7)$ & 0 & $3(100)$ \\
\hline Obese & 0 & & $2(100)$ & 0 & 0 & $2(100)$ & $1(50.0)$ & $1(50.0)$ \\
\hline \multicolumn{9}{|c|}{ Upper Arm Circumference (UAC) } \\
\hline $\begin{array}{l}\text { Good } \\
\text { Nutrition }\end{array}$ & $7(100)$ & 0 & & $5(71.4)$ & $2(28.6)$ & 0 & $1(14.3)$ & $6(85.7)$ \\
\hline $\begin{array}{l}\text { Bad } \\
\text { Nutrition }\end{array}$ & $33(68.8)$ & & $(31.3)$ & $10(20.8)$ & $28(58.3)$ & $10(20.8)$ & $15(31.3)$ & $33(68.8)$ \\
\hline \multicolumn{9}{|c|}{ Hemoglobin Status } \\
\hline Low 2 & $26(76.5)$ & & & $11(32,4)$ & $19(55.9)$ & $4(11.8)$ & $9(26,5)$ & $25(73.5)$ \\
\hline Normal & $14(66.7)$ & 7( & 3.3) & $4(19.4)$ & $11(52.4)$ & $6(28.6)$ & $7(33,3)$ & $14(66.7)$ \\
\hline
\end{tabular}

From the BMI of women of reproductive age based on the length of the respondents following a vegetarian diet which indicates that there were 16 respondents who followed a vegetarian diet of less than 10 years. From those respondents, there were $2(15.4 \%)$ respondents who had malnutrition, $13(35.1 \%)$ respondents with normal nutrition, and only 1 $(6.3 \%)$ respondents were said to be obese. While there were 39 respondents who followed a vegetarian diet of more than 10 years. And from those respondetns, 11 (84.6\%) respondents had malnutrition, $24(64.9 \%)$ with normal nutrition, $3(100 \%)$ respondents with over nutrition, and only $1(2.6 \%)$ respondents was said to be obese.

$\mathrm{Hb}$ levels for 16 respondents who followed a vegetarian diet of less than 10 years showed that $9(26.5 \%)$ respondents with low Hb levels and 7 (33.3\%) respondents had normal $\mathrm{Hb}$ 
levels. While 39 respondents who followed a vegetarian diet of more than 10 years showed that $25(73.5 \%)$ had low Hb levels and 14 (66.7\%) respondents with normal Hb levels

Nutritional status according to UAC assessed from 16 women of reproductive age who followed a vegetarian diet for less than 10 years indicated that as many as $1(14.3 \%)$ respondent had poor nutrition and as many as $15(31.3 \%)$ respondents who had good nutrition. While in 39 respondents who followed a vegetarian diet of more than 10 years, it was found that as many as $6(85.7 \%)$ respondents had malnutrition and $33(68.8 \%)$ respondents had good nutrition.

\subsection{Nutritional Status Based on BMI}

The results of the study on nutritional status based on BMI in women of reproductive age who followed a vegetarian diet in Asram Nitai Gauranga and Asram Radha Rasesvara showed that the majority of respondents could be included in the normal nutrition category with $67.3 \%$ of respondents. In addition to normal nutrition, this study also found that there were nutritional problems faced, including poor nutrition and over nutrition. The problem of malnutrition is the most nutritional problem experienced by women of reproductive age [7], which is in this reseach, the amount is equal to $23.6 \%$ of respondents. Whereas obesity problem is only $5.5 \%$. However, the results of this study are different from the results of the Sesanti's research (2012) which explains that the body mass index (BMI) of $60 \%$ in women of reproductive age who follow a vegetarian diet is declared undernourished or underweight [5]. This can be caused because nutritional status is influenced by diet or food intake, knowledge, economy, social culture, body condition and nutritional status in the past [3].

\subsection{Nutritional Status Based on Hb Levels}

With regard to the nutritional status based on $\mathrm{Hb}$ levels in women of reproductive age, it was found that $61.8 \%$ of respondents having anemia or with low Hb levels. According to the American Dietetic Association, basically iron needs are said to be high in vegetarian groups and post-menstrual women. This also proves that women are a group at risk of iron deficiency [8].

Vegetarian diets have different qualities and quantities, especially sources of iron. Vegetarian sources of iron come from non-heme iron, which is from plants. Non-heme iron is strongly influenced by factors that inhibit the absorption of iron, namely phytic acid found in beans (soybeans), oxalic acid in vegetables (lettuce, cabbage, cauliflower, beans and green beans), and tannins which is found in of tea and coffee, while heme iron is not affected by these factors $[4,9]$.

The Pasricha's study in 2013 stated that of the $20 \%$ of non-heme iron consumed, only $5 \%$ of non-heme iron in food can be absorbed. This is also due to the high factor of Fe absorption inhibitors as described previously [10]. To avoid anemia due to iron deficiency in the vegetarian group, vitamin $\mathrm{C}$ is needed to help the absorption of non-heme iron by reducing ferric iron to ferro in the small intestine so that it is easily absorbed. Vitamin $\mathrm{C}$ inhibits the formation of hemosiderin which is difficult to mobilize to free iron if needed. Non-heme iron absorption increases four-fold if there is vitamin C. Thus the risk of iron deficiency anemia can be avoided [11].

\subsection{Nutritional Status Based on Upper Arm Circumference}

Nutritional status based on upper arm circumference in this study showed that most women of reproductive dage had good nutrition with $87.3 \%$. This is because a vegetarian diet 
tends to be rich in nutrients contained in grains, vegetables, and fruits. This diet is also rich in carbohydrates contained in grains. Carbohydrates are one of the nutrients that are an energy source other than protein and fat. In the market there are many types of vegetarian food derived from grains processed into foods that resemble animal ingredients such as satay, meatballs, chicken, fish, and others. In addition, in this study the respondents run a type of lacto vegetarian which means impure vegetarianism. Therefore energy consumption from protein and fat is also obtained from milk [12 - 13].

\subsection{Reproductive Women Nutritional Status by Age}

Based on BMI and UAC, malnutrition problems were most prevalent in the 15-19 year age group, namely $69.2 \%$ according to BMI, and as much as $71.4 \%$ according to UAC. At that age, women aged 15-19 who are said to be teenagers are vulnerable to nutritional problems. Because in the adolescent phase there are physical changes and sexual maturity. If one does not pay attention to nutritional needs, it will have an impact on being malnourished, so that it will affect growth and development in young women and subsequently will affect the pregnancy in the future [14]. Based on $\mathrm{Hb}$ levels, most of the 20-35 year age group experienced anemia or low $\mathrm{Hb}$ levels of $55.9 \%$. This can be caused by the age group including the age of active reproduction. Where women of reproductive age experience pregnancy, breastfeeding, or bleeding during menstruation, much iron intake are required [14].

\subsection{Nutritional Status by Work}

Based on BMI, $84.6 \%$ of respondents who worked experienced problems with malnutrition. According to the previous research, there is a significant relationship between nutritional status and work fatigue [15]. The worse the nutritional status of female workers, the higher the level of fatigue of their work. Based on Hb levels, it was also found that as many as $76.5 \%$ of respondents had low Hb levels in the group of women of reproductive age who had jobs. Low $\mathrm{Hb}$ or anemia results in a decrease in learning ability, a decrease in physical activity or physical labor, and a decrease in body resistance to fatigue. So that this can affect work [15-16].

\subsection{Nutritional Status Based on the Length of Following the Vegetarian Diet}

Nutritional status according to how long women of reproductive age follow vegetarianism, showed that there are differences in nutritional status between women who follow more than 10 years of vegetarianism and those who follow it for less than 10 years. The problem of malnutrition is most experienced in women who follow a vegetarian diet of more than 10 years, compared to those who follow vegetarianism for less than 10 years with as much as $84.6 \%$ which is seen based on BMI. From the results of nutritional status based on age, the age of 15-19 years had the most malnutrition status. At the time of adolescent vegetarian girls of reproductive age already have less nutrition. And it has the tendency to be lower later on. One of the factors causing nutritional problems is eating habits. If someone is accustomed to following the vegetarian diet for years, eating improperly without knowing the need for various nutrients, it will have an impact on nutritional status and the lack of fulfillment of these nutrient requirements [15-16].

\section{Conclusions}


Based on the results of research conducted in Asram Nitai Gaurangga and Radha Rasevara Asram with a total of 55 respondents, it can be concluded that: for nutritional status based on BMI, 37 (67.3\%) respondents had normal nutrition, 13 (23.6\%) had malnutrition, $3(5.5 \%)$ with over nutrition, and $2(3.6 \%)$ obesity; for nutritional status based on UAC, $48(87.3 \%)$ respondents had good nutrition, and as many as $7(12.7 \%)$ had malnutrition; and for nutritional status based on $\mathrm{Hb}$ levels, $34(61.8 \%)$ respondents had low $\mathrm{Hb}$ levels or anemia, while 21 (38.2\%) had normal Hb levels.

Acknowledgement

Thank you to all the academics who have helped carry out this research. Thank you also to all respondents who were willing to participate in this study..

\section{References}

[1] Almatsier S 2011 Prinsip Dasar Ilmu Gizi (Jakarta - Gramedia Pustaka Umum).

[2] Mittal M 2013 To Assess The Nutritional Status and Morbidity Patterns Among Non- Pregnant Non-Lactating Rural Women of Reproductiv Age Group (18-40 Years) International Journal of Scientific and Research Publications 3 p2250-3153

[3] Kaushik N K, Aggrawal A, Singh M, Deswal S, Kaushik P 2015 Vegetarian Diets: Health Benefits and Associated Risks International Archives of Integrated Medicine 3 p207- 209

[4] Saunders A V, Craig W J, Baines S K, Posen J S 2013 Iron And Vegetarian Diets Med. J. Aust. 199(4) pS11-S16

[5] Sesanti 2012 Status Gizi Kelompok Lacto Vegetarian dan Kelompok Vegan di Pusdiklat Maitreyawira (Jakarta-Universitas Negeri Jakarta).

[6] Shrivastava S R, Shrivastava P S, Ramasamy J 2014 Assessment of Nutritional Status in The Community and Clinical Settings J. Med. Sci. 34(5) p211-213

[7] ESHRE Capri Working Group 2006 Nutrition and Reproduction in Women Hum. Reprod. Update 12(3): 193-207

[8] American Dietetic Association 2015 Position of the Academy of Nutrition and Dietetics: Vegetarian Diets J Acad Nutr Diet 115 p801- 810

[9] K L Beck, Conlon C A, Kruger R, Coad J 2014 Dietary Determinants of and Possible Solutions to Iron Deficiency for Young Women Living in Industrialized Countries: A Review Nutrients 6(9) p3747-3776

[10] Pasricha 2013 Diagnosis and Management of Iron Deficiency Anaemia: A Clinical Update MJA 193

[11] Hurrel R, Egli I 2010 Iron Bioavailability and Dietary Reference Values ACJN 91(5) p1461s$1467 \mathrm{~s}$

[12] Phillips F 2005 Vegetarian Nutrition Nutrition Bulletin 30 p132-167

[13] Mc Evoy C, Temple N J, Woodside J V 2012 Vegetarian Diets, Low Meat Diets, and Health: A Review Public Health Nutrition 15(12) p1-8

[14] Roberts, Bonnie S Worthington 2013 Nutrition Throughout The Life Cycle (Singapore - Mc Graw-Hill)

[15] Schluter K, van Eckert S 2017 Physical Condition, Nutritional Status, Fatigue, and Quality of Life in Oncological Outpatients SAGE Open Med 52050312117743674

[16]Lee B R, Ko Y M, Cho M H, Yoon Y R, Kye S H, Park Y K 2016 Effects of 12-Week Vegetarian Diet on the Nutritional Status, Stress Status, and Bowel Habits in Middle School Students and Teachers Clin Nutr Res 5(2) p 102-111 